\title{
Fighting cancer from different signalling pathways: Effects of the proteasome inhibitor Bortezomib in combination with the polo-like-kinase-1-inhibitor BI2536 in SCCHN
}

\author{
MARTIN LEINUNG, DANIEL HIRTH, AYKUT TAHTALI, MARC DIENSTHUBER, \\ TIMO STÖVER and JENS WAGENBLAST \\ ENT Department, Medical School, Goethe University, Frankfurt am Main, Germany
}

Received May 30, 2012; Accepted September 4, 2012

DOI: $10.3892 / \mathrm{ol} .2012 .927$

\begin{abstract}
Inhibition of the proteasome with Bortezomib as well as inhibition of Polo-like-kinase-1 (PLK-1) has been shown to be effective in many solid tumour models and also in squamous cell carcinoma of the head and neck (SCCHN) cell lines. For the first time, we systematically examined the antitumour effect of Bortezomib in combination with BI2536 in SCCHN in an in vitro study. Dose escalation studies were performed with nine SCCHN cell lines using Bortezomib and BI2536 as single agent and combination treatments. Growth-inhibitory and pro-apoptotic effects were measured quantitatively using cytohistology and Human Apoptose Array kit. The combination of Bortezomib and BI2536 showed significant anti-proliferative and apoptotic activity in all SCCHN cell lines investigated $(\mathrm{P}=0.008)$ compared to both the untreated control group and Bortezomib alone. A combination treatment regime consisting of the proteasome inhibitor, Bortezomib, and the inhibitor of PLK-1, BI2536, leads to an enhanced anti-proliferative and apoptotic effect in SCCHN cell lines, compared to single agent treatment with Bortezomib alone.
\end{abstract}

\section{Introduction}

Head and neck cancer is one of the most common cancerous diseases worldwide. Each year more than 500,000 new cases are diagnosed (1). These are mostly malignancies of the upper aerodigestive tract, including the mouth, larynx and pharynx region from the base of the skull up to the upper oesophagus. Currently, standard treatment regimes include surgery, radiation and chemotherapy. In approximately $50 \%$

Correspondence to: Dr Jens Wagenblast, ENT Department, University Hospital, Theodor-Stern-Kai 7, D-60590 Frankfurt am Main, Germany

E-mail: jens.wagenblast@kgu.de

Key words: Bortezomib, BI2536, squamous cell head and neck carcinoma cell lines (SCCHN), growth inhibition, apoptosis of all cases a tumour relapse has been observed to correlate with a poor prognosis $(2,3)$. Standard chemotherapeutical regimes including cisplatin and 5-FU are often associated with adverse toxicity. In the last decade there has been an introduction of well-tolerated agents in head and neck cancer therapy, such as cetuximab, a chimeric monoclonal inhibitor of the epidermal growth factor (EGF) receptor. This agent binds with high affinity to the extracellular domain of the EGF receptor being overexpressed in squamous cell carcinoma of the head and neck (SCCHN). The addition of cetuximab to conventional chemotherapy or standard radiation therapy was found to significantly enhance patient survival (4). However, despite the success of cetuximab for use in SCCHN patients, improvement in overall survival with the use of this agent has only been incremental in the past. Thus, there is a strong need for alternative or additive drug regimens for the treatment of head and neck cancer $(5,6)$. In previous reports we showed a significant anti-proliferative and apoptotic effect of Bortezomib and BI2536 in SCCHN $(7,8)$. Nuclear factor- $\kappa \mathrm{B}$ $(\mathrm{NF}-\kappa \mathrm{B})$ is a protein which is overexpressed in SCCHN (9). In several gene expression studies it was shown that tumours with high risk of recurrence harboured a higher expression of genes associated with the activation of $\mathrm{NF}-\kappa \mathrm{B}$ signalling (10). Bortezomib is a small-molecule proteasome inhibitor. While it affects various signalling pathways, one of the mechanisms of antitumour activity is NF- $\kappa \mathrm{B}$ inhibition (11). BI2536 is another selective and potent small-molecule drug that inhibits pololike-kinase-1 (PLK-1), which plays a key role in processes such as cell division and checkpoint regulation of mitosis. Approximately $80 \%$ of human tumours express high levels of PLK transcripts, while PLK mRNA is mostly absent in healthy surrounding tissue $(12,13)$. This PLK overexpression is associated with poor prognosis and a lower overall survival rate. The aim of the present study was to illuminate the combinational effects of Bortezomib and BI2536 in SCCHN.

\section{Material and methods}

Nine different squamous carcinoma cell lines, predominantly of head and neck origin, were tested in this study. A-431 cells were obtained from American Type Culture Collection (ATCC). PE/CA-PJ 15, PE/CA-PJ 34, PE/CA-PJ 41 and 
Table I. Concentration of Bortezomib and BI2536 in different cell lines.

\begin{tabular}{lcc}
\hline $\begin{array}{l}\text { Tumour } \\
\text { cell line }\end{array}$ & $\begin{array}{c}\text { Concentration of } \\
\text { Bortezomib }(\mu \mathrm{M})\end{array}$ & $\begin{array}{c}\text { Concentration of } \\
\text { BI2536 }(\mathrm{nM})\end{array}$ \\
\hline PE/CA-PJ 15 & 2.50 & 2.50 \\
PE/CA-PJ 34 & 5.00 & 2.50 \\
PE/CA-PJ 41 & 2.50 & 2.50 \\
PE/CA-PJ 49 & 1.25 & 2.50 \\
CLS-354 & 1.25 & 2.50 \\
UM-SCC-14C & 2.50 & 2.50 \\
Cal-27 & 2.50 & 2.50 \\
Kyse-140 & 2.50 & 2.50 \\
A-431 & 2.50 & 2.50 \\
\hline
\end{tabular}

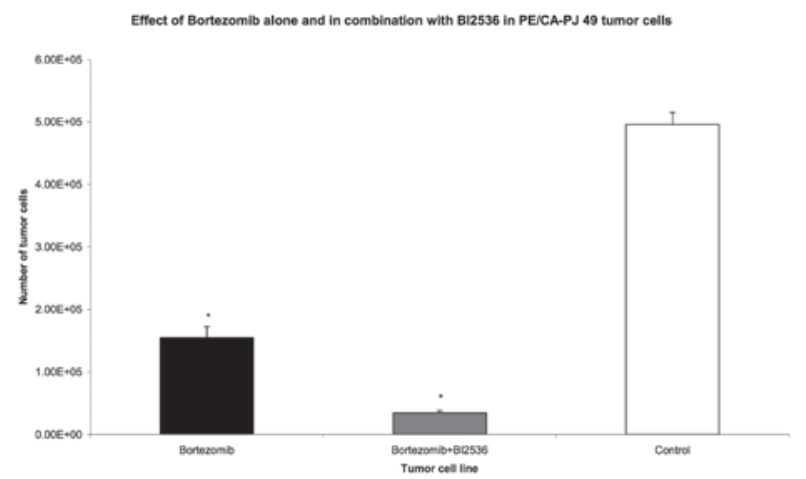

Figure 1. Growth-inhibitory effect of Bortezomib as a single agent and in combination with BI2536 at a fixed cell line-specific concentration (as shown in Table I) after $72 \mathrm{~h}$ treatment in the PE/CA-PJ 49 tumour cell line. The corresponding untreated tumour cell line (white column) served as a control and was incubated according to the instructions of the suppliers, with only antibiotics at $37^{\circ} \mathrm{C}$ in the cell type-specific medium Quantum 263 with L-glutamine. The absolute tumour cell numbers in treated and control cell lines were determined in a Rosenthal chamber at $72 \mathrm{~h}$ after treatment or incubation with Quantum 263 (controls), respectively. Mean values of three independent experiments with standard deviations are shown. Single agent differences versus combination treatment and untreated controls are indicated by asterisks. Combination treatment of Bortezomib with BI2536 inhibited cell proliferation significantly more than mono-drug therapy with Bortezomib alone ( $\mathrm{P}=0.008)$.

PE/CA-PJ 49 cells were obtained from European Collection of Cell Cultures (ECACC), and Cal-27 and Kyse-140 cells from DSMZ GmbH (Braunschweig, Germany). CLS-354 and UM-SCC-14C cells were obtained from Cell Lines Service (CLS; Eppelheim, Germany). The fibroblast cell line was a gift from the Department of Dermatology, University Hospital, Frankfurt/Main, Germany. Bortezomib (Velcade ${ }^{\circledR}$ ) was supplied by Millenium Pharmaceuticals Inc. (Cambridge, MA, USA) and Johnson \& Johnson Pharmaceuticals (Raritan, NJ, USA). BI2536 was provided by Boehringer Ingelheim $\mathrm{GmbH}$ (Ingelheim am Rhein, Austria). Squamous carcinoma cell lines were cultivated, according to the instructions of the suppliers, with antibiotics at $37^{\circ} \mathrm{C}$ in the cell type-specific medium Quantum 263 with L-glutamine (PAA Laboratories $\mathrm{GmbH}$, Pasching, Austria). Cells were seeded in 96-well plates $\left(1 \times 10^{5}\right.$ cells/well), and after incubation for $24 \mathrm{~h}$, the cells were treated with Bortezomib and/or BI2536 for 24, 48 and $72 \mathrm{~h}$,

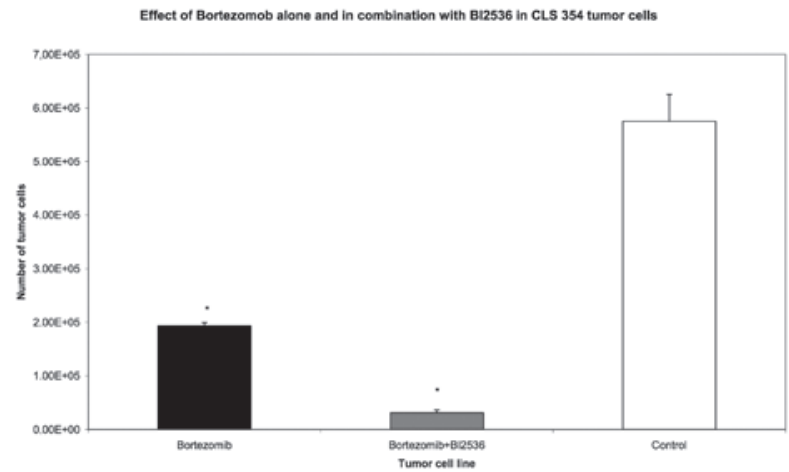

Figure 2. Growth-inhibitory effect of Bortezomib as a single agent and in combination with BI2536 at a fixed cell line-specific concentration (as shown in Table I) after $72 \mathrm{~h}$ treatment in the CLS-354 tumour cell line. The corresponding untreated tumour cell line (white column) served as a control and was incubated according to the instructions of the suppliers, with only antibiotics at $37^{\circ} \mathrm{C}$ in the cell type-specific medium Quantum 263 with L-glutamine. The absolute tumour cell numbers in treated and control cell lines were determined in a Rosenthal chamber at $72 \mathrm{~h}$ after treatment or incubation with Quantum 263 (controls), respectively. Mean values of three independent experiments with standard deviations are shown. Single agent differences versus combination treatment and untreated controls are indicated by asterisks. Combination treatment of Bortezomib with BI2536 inhibited cell proliferation significantly more than mono drug therapy with Bortezomib alone $(\mathrm{P}=0.008)$.

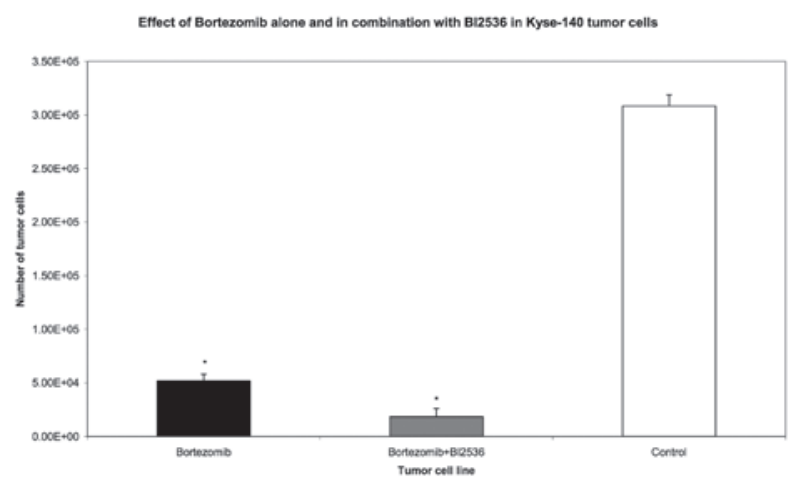

Figure 3. Growth-inhibitory effect of Bortezomib as a single agent and in combination with BI2536 at a fixed cell line-specific concentration (as shown in Table I) after $72 \mathrm{~h}$ treatment in the Kyse-140 tumour cell line. The corresponding untreated tumour cell line (white column) served as a control and was incubated according to the instructions of the suppliers, with only antibiotics at $37^{\circ} \mathrm{C}$ in the cell type-specific medium Quantum 263 with L-glutamine The absolute tumour cell numbers in treated and control cell lines were determined in a Rosenthal chamber at $72 \mathrm{~h}$ after treatment or incubation with Quantum 263 (controls), respectively. Mean values of three independent experiments with standard deviations are shown. Single agent differences versus combination treatment and untreated controls are indicated by asterisks. Combination treatment of Bortezomib with BI2536 inhibited cell proliferation significantly more than mono-drug therapy with Bortezomib alone ( $\mathrm{P}=0.008)$.

respectively. In the experiments described in this publication, Bortezomib and BI2536 were used in each cell line at a fixed, cell line-specific concentration that had produced maximum growth inhibition in previous systematic investigations in our laboratory. The concentration for all cell lines investigated was $2.5 \mathrm{nmol} / 1$ for BI2536, which showed maximal growth inhibition in our previous dose escalation studies. The concentration for Bortezomib ranged from 1.25 to $5 \mu \mathrm{M}$ (Table I). 
Cells were counted in a Rosenthal chamber at 24, 48 and $72 \mathrm{~h}$ after treatment. Apoptosis was detected by microscopic cytohistology as well as by Human Apoptose Array kit (R\&D Systems, Abingdon, UK) as previously described by other groups $(14,15)$.

Each experiment was performed in triplicate. For statistical analysis, a Wilcoxon test for matched pairs (dependent samples) was performed using SPSS 19.0 software for Windows. $\mathrm{P}<0.05$ was considered to indicate a statistically significant difference.

\section{Results}

Nine different squamous carcinoma cell lines, predominantly of head and neck origin, were tested in this study. After incubation for $24 \mathrm{~h}$, the cells were treated with Bortezomib or BI2536 alone, or with a combination of both agents for 24, 48 and $72 \mathrm{~h}$, respectively. Compared with the untreated control group, the proteasome inhibitor, Bortezomib, as well as the PLK-1 inhibitor, BI2536, had highly significant anti-proliferative and apoptotic activity when used as single agent treatments in all nine tumour cell lines $(\mathrm{P}=0.008)$. The drug combination of Bortezomib and BI2536 showed a significantly higher antiproliferative activity compared with Bortezomib alone $(\mathrm{P}=0.008)$ (Figs. 1-3). Apoptosis was detected by microscopic cytohistology as well as by Human Apoptose Array kit detecting pro caspase 3 as a typical molecular apoptosis marker.

These results demonstrate that the combination of proteasome inhibitor, Bortezomib, with the PLK-1 inhibitor, BI2536, enhances the apoptotic effects of Bortezomib alone and thus leads to a significantly higher anti-proliferative effect.

\section{Discussion}

Head and neck cancer is one of the most common cancer types worldwide and is associated with many different sites in the upper aerodigestive tract. Although surgical techniques and pharmacological regimens have been improved in the past decades, there has been little improvement in the 5 -year survival rate for patients suffering from these types of malignant tumours (2). Often there is a tumour relapse, which is typically resistant to conventional antineoplastic drugs (3). This fact among others, underlines the great need to develop new therapeutic regimens which are potent on one hand and well tolerated on the other. Therefore, identifying new targets with special regard to the various signalling pathways is one of the greatest challenges at present. Several in vitro and in vivo studies showed the proteasome inhibitor Bortezomib to effectively inhibit tumour growth, induce apoptosis and lower vessel density in SCCHN (7,16-19). Furthermore, Bortezomib led to a sustained but limited response rate in SCCHN patients suffering from tumour recurrence, who underwent radiation therapy combined with Bortezomib $(20,21)$. With regard to these findings, it may be possible that optimisation of Bortezomib efficacy may yield substantial improvement in the therapy of head and neck cancer although the use of Bortezomib in SCCHN is discussed controversially in the literature $(22,23)$. PLK-1 is the most thoroughly characterised member of the polo family and is known to control critical steps in the passage of cells through the $\mathrm{M}$ phase of the cell cycle, initiating the entry into mitosis, centrosome separation necessary for the formation of a bipolar mitotic spindle, metaphase to anaphase transition, mitotic exit and finally, the onset of cell division (12). BI2536 is a highly selective and potent small-molecule PLK-1 inhibitor.

In a previous study we demonstrated that BI2536, when applied as a single agent, showed strong inhibition of cell proliferation accompanied by enhanced apoptosis in nine different squamous carcinoma cell lines (unpublished results). In the present study, we examined the effects of combination therapy of Bortezomib and BI2536 together in SCCHN cell lines, for the first time. Our results showed that compared with the untreated control group, the proteasome inhibitor Bortezomib, as well as the PLK-1 inhibitor BI2536, had a highly significant anti-proliferative and apoptotic activity when used as single agent treatment in all nine tumour cell lines $(\mathrm{P}=0.008)$. Notably, the drug combination of Bortezomib and BI2536 showed significant higher anti-proliferative activity compared with Bortezomib alone $(\mathrm{P}=0.008)$. These findings indicate that the antiproliferative effect of proteasome inhibitior Bortezomib is enhanced by adding BI2536.

With regard to the complex mechanism of tumour biology, and with special regard to the different signalling pathways that play an important role in tumour genesis, this study introduces the concept that a cancer may be treated successfully by targeting several pathways at the same time.

Although Bortezomib showed a notable anticancer activity in previous in vitro and in vivo set-ups, its clinical activity in solid tumours is still limited (24-26). Therefore, new combination regimens targeting the tumour from different signalling pathways may be one key to success. Due to our favourable results presented, the addition of BI2536 to Bortezomib in SCCHN treatment may be subject to further pre-clinical and clinical phase I investigations.

\section{Acknowledgements}

The authors thank Boehringer Ingelheim GmbH for the donation of BI2536. The authors thank Erika Weith for her excellent technical support.

\section{References}

1. Jemal A, Siegel R, Ward E, Hao Y, Xu J and Thun MJ: Cancer statistics, 2009. CA Cancer J Clin 59: 225-249, 2009.

2. Forastiere A, Koch W, Trotti A and Sidransky D: Head and neck cancer. N Engl J Med 345: 1890-1900, 2001.

3. Gibson MK and Forastiere AA: Reassessment of the role of induction chemotherapy for head and neck cancer. Lancet Oncol 7: 565-574, 2006

4. Specenier P and Vermorken JB: Cetuximab in the treatment of squamous cell carcinoma of the head and neck. Expert Rev Anticancer Ther 11: 511-524, 2011.

5. Gibson MK, Li Y, Murphy B, Hussain MH, DeConti RC, Ensley J, et al: Randomized phase III evaluation of cisplatin plus fluorouracil versus cisplatin plus paclitaxel in advanced head and neck cancer (E1395): an intergroup trial of the Eastern Cooperative Oncology Group. J Clin Oncol 23: 3562-3567, 2005.

6. Burtness B, Goldwasser MA, Flood W, Mattar B and Forastiere AA. Phase III randomized trial of cisplatin plus placebo compared with cisplatin plus cetuximab in metastatic/recurrent head and neck cancer: an Eastern Cooperative Oncology Group study. J Clin Oncol 23: 8646-8654, 2005.

7. Wagenblast J, Hambek M, Baghi M, Gstottner W, Strebhardt K, Ackermann $\mathrm{H}$, et al: Antiproliferative activity of bortezomib alone and in combination with cisplatin or docetaxel in head and neck squamous cell carcinoma cell lines. J Cancer Res Clin Oncol 134: 323-330, 2008. 
8. Wagenblast J, Baghi M, Arnoldner C, Bisdas S, Gstottner W, Ackermann $\mathrm{H}$, et al: Cetuximab enhances the efficacy of bortezomib in squamous cell carcinoma cell lines. J Cancer Res Clin Oncol 135: 387-393, 2009.

9. Zhang PL, Pellitteri PK, Law A, Gilroy PA, Wood GC, Kennedy TL, et al: Overexpression of phosphorylated nuclear factor-kappa B in tonsillar squamous cell carcinoma and highgrade dysplasia is associated with poor prognosis. Mod Pathol 18: 924-932, 2005

10. Chung CH, Parker JS, Ely K, Carter J, Yi Y, Murphy BA, et al: Gene expression profiles identify epithelial-to-mesenchymal transition and activation of nuclear factor- $\mathrm{\kappa} \mathrm{B}$ signaling as characteristics of a high-risk head and neck squamous cell carcinoma. Cancer Res 66: 8210-8218, 2006.

11. Adams J, Palombella VJ, Sausville EA, Johnson J, Destree A, Lazarus DD, et al: Proteasome inhibitors: a novel class of potent and effective antitumor agents. Cancer Res 59: 2615-2622, 1999.

12. Schoffski P: Polo-like kinase (PLK) inhibitors in preclinical and early clinical development in oncology. Oncologist 14: 559-570, 2009.

13. Schoffski P, Blay JY, De Greve J, Brain E, Machiels JP, Soria JC, et al: Multicentric parallel phase II trial of the polo-like kinase 1 inhibitor BI 2536 in patients with advanced head and neck cancer, breast cancer, ovarian cancer, soft tissue sarcoma and melanoma. The first protocol of the European Organization for Research and Treatment of Cancer (EORTC) Network Of Core Institutes (NOCI). Eur J Cancer 46: 2206-2215, 2010.

14. Datta D, Banerjee P, Gasser M, Waaga-Gasser AM and Pal S: CXCR3-B can mediate growth-inhibitory signals in human renal cancer cells by down-regulating the expression of heme oxygenase-1. J Biol Chem 285: 36842-36848, 2010.

15. Ray RB, Raychoudhuri A, Steele R and Nerurkar P: Bitter melon (Momordica charantia) extract inhibits breast cancer cell proliferation by modulating cell cycle regulatory genes and promotes apoptosis. Cancer Res 70: 1925-1931, 2010.

16. Lun M, Zhang PL, Pellitteri PK, Law A, Kennedy TL and Brown RE: Nuclear factor- $\kappa \mathrm{B}$ pathway as a therapeutic target in head and neck squamous cell carcinoma: pharmaceutical and validation in human cell lines using Velcade and siRNA/N molecular F-кB. Ann Clin Lab Sci 35: 251-258, 2005.

17. Sunwoo JB, Chen Z, Dong G, Yeh N, Crowl Bancroft C, Sausville E, et al: Novel proteasome inhibitor PS-341 inhibits activation of nuclear factor- $\kappa \mathrm{B}$, cell survival, tumor growth, and angiogenesis in squamous cell carcinoma. Clin Cancer Res 7: 1419-1428, 2001.
18. Fribley A, Zeng Q and Wang CY: Proteasome inhibitor PS-341 induces apoptosis through induction of endoplasmic reticulum stress-reactive oxygen species in head and neck squamous cell carcinoma cells. Mol Cell Biol 24: 9695-9704, 2004.

19. Li C, Li R, Grandis JR and Johnson DE: Bortezomib induces apoptosis via Bim and Bik up-regulation and synergizes with cisplatin in the killing of head and neck squamous cell carcinoma cells. Mol Cancer Ther 7: 1647-1655, 2008.

20. Allen C, Saigal K, Nottingham L, Arun P, Chen Z and Van Waes C. Bortezomib-induced apoptosis with limited clinical response is accompanied by inhibition of canonical but not alternative nuclear factor- $\kappa \mathrm{B}$ subunits in head and neck cancer. Clin Cancer Res 14: 4175-4185, 2008.

21. Van Waes C, Chang AA, Lebowitz PF, Druzgal CH, Chen Z, Elsayed YA, et al: Inhibition of nuclear factor- $\kappa \mathrm{B}$ and target genes during combined therapy with proteasome inhibitor bortezomib and reirradiation in patients with recurrent head-andneck squamous cell carcinoma. Int J Radiat Oncol Biol Phys 63 : 1400-1412, 2005.

22. Argiris A, Duffy AG, Kummar S, Simone NL, Arai Y, Kim SW, et al: Early tumor progression associated with enhanced EGFR signaling with bortezomib, cetuximab, and radiotherapy for head and neck cancer. Clin Cancer Res 17: 5755-5764, 2011.

23. Li C, Zang Y, Sen M, Leeman-Neill RJ, Man DS, Grandis JR, et al: Bortezomib up-regulates activated signal transducer and activator of transcription-3 and synergizes with inhibitors of signal transducer and activator of transcription-3 to promote head and neck squamous cell carcinoma cell death. Mol Cancer Ther 8: 2211-2220, 2009.

24. Davis NB, Taber DA, Ansari RH, Ryan CW, George C, Vokes EE, et al: Phase II trial of PS-341 in patients with renal cell cancer: a University of Chicago phase II consortium study. J Clin Oncol 22: 115-119, 2004

25. Papandreou CN, Daliani DD, Nix D, Yang H, Madden T, Wang X, et al: Phase I trial of the proteasome inhibitor bortezomib in patients with advanced solid tumors with observations in androgen-independent prostate cancer. J Clin Oncol 22: 2108-2121, 2004

26. Shah MH, Young D, Kindler HL, Webb I, Kleiber B, Wright $\mathrm{J}$, et al: Phase II study of the proteasome inhibitor bortezomib (PS-341) in patients with metastatic neuroendocrine tumors. Clin Cancer Res 10: 6111-6118, 2004. 